Available online at http://jddtonline.info

RESEARCHARTICLE

\title{
SELF-NANO EMULSIFYING DRUG DELIVERY SYSTEM (SNEDDS) FOR ORAL DELIVERY OF ATORVASTATIN- FORMULATION AND BIOAVAILABILITY STUDIES
}

\author{
Venkatesh Miryala, Mallesh Kurakula*
}

Department of Pharmaceutics, Lalitha college of Pharmacy, Venkatapur, Ghatkesar,

\author{
R.R district, Andhra Pradesh, INDIA
}

Address for Correspondence: Mallesh Kurakula, Masters in Pharmacy, Department of pharmaceutics, lalitha college of pharmacy, Hyderabad, India.Phone: 91 9550645635, Email:mallesh_kurakula@yahoo.com.

\begin{abstract}
:
The aim of the study was to develop a self-nano emulsifying drug delivery system (SNEDDS) for the atorvastatin which belongs to BCS class II lipid lowering agent with poor water solubility and dissolution rate. The solubility of atorvastatin in individual micro emulsion components viz. oil and surfactants was determined. The surfactants were screened for emulsification ability. Based on the solubility determinations and emulsification properties oleic acid as oil; surfactants Brij 80 and Tween 80 were selected for further study. The solubility of atorvastatin in different ratios of selected oil and surfactants was determined. The composition of oil: Surfactant with maximum solubility for atorvastatin was used for SNEDDS formulation. Ternary phase diagrams were used to evaluate the micro emulsification existence area. The micro emulsions were evaluated for emulsion droplet size, self-emulsification time, phase separation, in vitro dissolution and stability. SNEDDS formulations found to be self-emulsified in 70 to 120 seconds without precipitation and their mean droplet sizes was 150 to $230 \mathrm{~nm}$. Among the optimized formulations, formulation BF4 showed highest in vitro drug release. Formulation BF4 was composed of $20 \%$ oleic acid, $60 \%$ tween 80 and $20 \%$ brij 30 showed significant increases in the dissolution rate (99.65\%) in 90 minutes and intestinal absorption $(86.67 \%)$ than marketed product with $56.86 \%$ release and $45.34 \%$ oral absorption. Stability studies were conducted according to the Q1 ICH guidelines and found stable at different conditions.
\end{abstract}

Key words: - Self-nano emulsifying drug delivery system, Atorvastatin, Hypercholestermia, Tween 80, Brij 30.

\section{INTRODUCTION:-}

Majority of drugs are frequently administered through oral route, but approximately $40 \%$ of new drug candidates have poor-water solubility and the oral delivery of such drugs is complicated for the reason that of their low bioavailability, high intra- and inter-subject variability, and not have dose linearity ${ }^{1,2}$. To overcome these problems, a variety of strategies have been developed including the use of surfactants $^{3}, \quad$ lipids $^{4}, \quad$ permeation enhancers ${ }^{4}$, micronization $^{5}$, salt formation ${ }^{6}$, cyclodextrins ${ }^{7}$, nanoparticles and solid dispersions ${ }^{4,5}$ etc. There has been emergent attention in the use of lipid excipients in selfemulsifying lipid formulations (SELFs) for the reason that of their capability to solubilize poorly water-soluble 'lipophilic' drugs and prevail over the problem of poor drug absorption and bioavailability ${ }^{8}$.

Micro emulsions and self-emulsifying systems have emerged as potential solubility enhancing technologies, whose solubilising and absorption promoting effect is thought to lay in the reactivity of triglycerides and surfactants with the walls of the gastrointestinal tract. Traditionally, long and medium-chain triglycerides (LCTs and MCTs, respectively) have been employed with surfactants to incorporate drugs into self- emulsifying systems $^{8}$. Non-ionic surfactants, such as Tweens (polysorbates) and labrafil (poly-oxy-ethylated oleic glycerides), with high hydrophile-lipophile balances (HLB) are often used to ensure immediate formation of oil-in-water $(\mathrm{o} / \mathrm{w})$ droplets during production ${ }^{9}$.

Amphiphilic, non-ionic surfactants allow higher degrees of drug solubilisation to occur and may prevent the precipitation of drug out of the micro-emulsion in vivo. Co-surfactants are frequently employed to increase the 2011, JDDT. All Rights Reserved amount of drug capable of being dissolved into the lipid base, because the concentration of surfactant in most selfemulsifying systems is required to be in excess of 30 per cent w/w. These co-surfactants are often organic solvents suitable for oral administration, such as ethanol, propylene glycol and poly ethylene glycol ${ }^{10}$. Most self-emulsifying systems are limited to administration in lipid-filled soft or hard-shelled gelatin capsules due to the liquid nature of the product. Interaction between the capsule shell and the emulsion should be considered so as to prevent the hydroscopic contents from dehydrating or migrating into the capsule shell ${ }^{11}$.

Atorvastatin, as a synthetic lipid-lowering agent, is an inhibitor of 3-hydroxy-3-methyl- glutaryl-coenzyme A (HMG CoA) reductase which catalyzes the conversion of HMG-Co A to mevalonate, an early rate-limiting step in cholesterol biosynthesis. Atorvastatin is currently used as calcium salt for the treatment of hypercholesterolemia. It is insoluble in aqueous solution of $\mathrm{pH} 4$ and below; it is very slightly soluble in water and $\mathrm{pH} 7.4$ phosphate buffer. The intestinal permeability of atorvastatin is high at the physiologically relevant intestinal $\mathrm{pH}$. However, it is reported that the absolute bioavailability $(F)$ of atorvastatin is $12 \%$ after a $40 \mathrm{mg}$ oral dose ${ }^{12}$. In present study SMEDDS of Atorvastatin was prepared for enhanced solubility and dissolution of poorly soluble drug.

\section{MATERIALS AND METHODS:}

Atorvastatin calcium (API), soybean oil, sunflower oil and olive oil obtained as a gift sample from Bright Labs, Hyderabad. Brij 30, Acetonitrile (HPLC grade), potassium dihydrogen phosphate, Ortho phosphoric acid (AR grade) 
were procured from Qualigens Ltd., Mumbai. Tween 80, oleic acid, PEG 400, methanol (AR grade) were procured from S.D Fine chemicals, Mumbai. HPLC grade water was obtained from SD-Lab star (3TWF-UV) water purification system.

\section{Solubility Studies:}

To quantify and understand the solubility studies of atorvastatin an analytical method using RP-HPLC (Shimadzu Prominence LC-20AD was developed, optimized and validated. The solubility of atorvastatin calcium in various oils (soybean, sunflower \& olive), surfactant and co-surfactants was measured using vial shake method. Unknown amount of selected vehicles was added to each cap vial containing an excess of atorvastatin , heated up to $40^{\circ} \mathrm{C}$ and centrifuged (Remi RM-12C centrifuge) at $3000 \mathrm{rpm}$ for $5 \mathrm{~min}$. Excess insoluble atorvastatin was discarded by filtration using a membrane filter $(0.45 \mu \mathrm{m}, 13 \mathrm{~mm})$. The concentration of atorvastatin was then quantified by RP-HPLC method (Shimadzu Prominence LC-20AD). Solubility study was performed at triplicate and standard deviation was calculated.

\section{Preliminary screening of surfactants:-}

Different surfactants for the per oral use were screened for emulsification ability. Briefly, $150 \mathrm{mg}$ of each surfactant was added to $150 \mathrm{mg}$ of the oily phase, heated up to $50^{\circ} \mathrm{C}$ and diluted to $100 \mathrm{ml}$ with water. Ease of emulsification was judged by the number of flask inversions required to yield homogenous emulsion. Emulsions were allowed to stand for 2 hours and their percentage transmittance was evaluated by UV-Visible spectrophotometer ${ }^{13}$ (Shimadzu, Japan). Emulsions were furthermore observed visually for any turbidity or phase separation. The selected oily phase and surfactant were used for further screening of the different co-surfactants (Brij 30 and tween 80) for their emulsification ability.

\section{Construction of Ternary phase diagram:}

The ability of oil within surfactant: co-surfactant that could self-emulsify under proper dilution can be identified and selected from ternary phase diagrams. Ternary phase diagram were constructed using water titration method. The mixture of oil with surfactant or combination of surfactant and co-surfactant were prepared in different ratios, titrated against water and agitated (Remi CM 101 DX) until slightly bluish emulsion was formed. Percentage of oil, surfactant: co-surfactant mixture and water was calculated using ternary phase diagram. CHEMEX 3.51 software tool was used to find out the emulsification zone ${ }^{14}$. Further the same procedure was repeated instead of oil surfactant mix to determine the effect of drug on phase diagram.

\section{Formulation of SNEDDS:}

$10 \mathrm{mg}$ of atorvastatin was dissolved in cosurfactant at $45^{\circ} \mathrm{C}$ in an isothermal water bath. After cooling, calculated amount oil and surfactant was added and sonicated (Citizen Digital, India) until a clear solution was obtained. The formulation was equilibrated at ambient temperature for at least 48 hours to examine the signs of turbidity or phase separation. Formulations made were examined for leakage by filling in hard gelatin capsules ${ }^{15}$.

Table1. Various Formulations using oil: co-surfactant/surfactant ratio

\begin{tabular}{|c|c|c|c|c|}
\hline Formulation code & Drug (mg) & \% Oleic acid & \% Tween 80 & \% Brij 30 \\
\hline BF1 & 10 & 5 & 47.5 & 47.5 \\
\hline BF2 & 10 & 5 & 63.33 & 31.66 \\
\hline BF3 & 10 & 10 & 45 & 45 \\
\hline BF4 & $\mathbf{1 0}$ & $\mathbf{1 0}$ & $\mathbf{6 0}$ & $\mathbf{3 0}$ \\
\hline BF5 & 10 & 15 & 42.5 & 42.5 \\
\hline BF6 & 10 & 20 & 56.66 & 28.33 \\
\hline BF7 & 10 & 20 & 40 & 40 \\
\hline BF8 & 10 & 25 & 53.33 & 26.66 \\
\hline BF9 & 10 & 25 & 37.5 & 37.5 \\
\hline BF10 & 10 & 25 & 50 & 25 \\
\hline BF11 & 10 & 30 & 35 & 35 \\
\hline BF12 & 10 & 30 & 46.66 & 46.66 \\
\hline BF13 & 10 & 35 & 32.5 & 32.5 \\
\hline BF14 & 10 & 35 & 43.33 & 21.66 \\
\hline BF15 & 10 & 40 & 30 & 30 \\
\hline BF16 & 10 & 40 & 40 & 20 \\
\hline BF17 & 10 & 45 & 27.5 & 27.5 \\
\hline BF18 & 10 & 45 & 36.66 & 18.33 \\
\hline BF19 & 10 & 50 & 25 & 25 \\
\hline BF20 & 10 & 50 & 33.33 & 16.66 \\
\hline
\end{tabular}

\section{Characterization:}

\section{Determination of self -emulsification time:}

The primary means of self-emulsification assessment is by visual evaluation. The efficiency of selfnano-emulsification is estimated by agitation at $100 \mathrm{rpm}$ in mixture of water and $0.1 \mathrm{~N} \mathrm{HCl}$ solution $(100 \mathrm{ml})$ at temperature $37^{\circ} \mathrm{C}^{15}$. The time required to form nanoemulsion depends upon dilution of SNEDDS with water.

\section{Visual observation, Phase separation and stability study of emulsion:}

Different formulations were diluted, agitated with $20 \mathrm{ml}$ of distilled water at $37^{\circ} \mathrm{C}$ and allowed to stand for 24 hours. Further visual observation was made to check the ISSN: 2250-1177

CODEN (USA): JDDTAO 
extent of phase separation and precipitation. Mixtures exhibiting a negligible phase separation during the 24 hour period were selected for further studies and evaluated on visibility grades ${ }^{16}$.

Table- 2 Visibility grades

\begin{tabular}{|c|c|}
\hline Grade & Dispersibility and appearances \\
\hline I & Clear or slightly bluish in appearance \\
\hline II & Bluish white appearance. \\
\hline III & Bright white emulsion (similar to milk \\
\hline IV & Dull, grayish white emulsion with a slightly oily appearance \\
\hline V & Turbid appearance \\
\hline
\end{tabular}

\section{Droplet size, Zeta potential and poly-dispersity} analysis:

The mean droplet size, zeta potential and polydispersity index of formulations was determined by using Zeta seizer HAS 3000 (Malvern Instruments Ltd., Malvern, UK). Light scattering was monitored at $25^{\circ} \mathrm{C}$ at a $90^{\circ}$ angle $^{16}$. The dispersed formulations were measured after dilutions $(1: 100)$.

\section{FTIR studies:}

Infrared (IR) spectroscopy studies were conducted using FTIR (Bruker Alpha T, Germany) at 4000 to $500 \mathrm{~cm}^{-1}$. Liquid sample preparations were made as per the instrument and the spectrum was recorded for various formulations ${ }^{17}$.

\section{Physical analysis:}

The surface morphology, roundness, formation of aggregates and size distribution of nano globules formed were studied by Scanning Electron Microscopy (Model: JSM-5510Jeol Ltd, Tokyo, Japan). 1gm of formulation was diluted with $10 \mathrm{ml}$ of $\mathrm{pH} 6.8$ phosphate buffer. The nano-emulsions were mounted on an aluminum stub using double-sided carbon adhesive tape. Then the vesicles were sputter-coated with gold palladium $(\mathrm{Au} / \mathrm{Pd})$ using a vacuum evaporator and examined with digital camera, at $20 \mathrm{kV}$ accelerating voltage ${ }^{17}$.

\section{Drug content:}

Various formulations equivalent to $10 \mathrm{mg}$ were taken into a standard volumetric flask, mixed and diluted with methanol. $1 \mathrm{ml}$ of this solution was diluted to $10 \mathrm{ml}$ with phosphate buffer $\mathrm{pH} \quad 6.8$; it gives $100 \mu \mathrm{g} / \mathrm{ml}$ (theoretical). Further drug content was quantified using RP-HPLC method developed at $246 \mathrm{~nm}$.

$$
\% \text { of drug }=\frac{\text { standard peak area }}{\text { sample peak area }} \times 100
$$

\section{Standard peak area at $100 \mu \mathrm{g} / \mathrm{ml}$}

\section{Cloud point measurement:}

Formulations were diluted with $50 \mathrm{ml}$ of water and placed on a water bath with gradually increase the temperature until the diluted formulation turned to cloudy.
It gives the information about the stability of the nanoemulsion at body temperature ${ }^{18}$.

\section{In vitro release study:}

Quantitative in vitro release test was performed using USP XXIV method (dissolution apparatus \#2, at 50 $\mathrm{rpm}$ ) in $900 \mathrm{ml} 0.05 \mathrm{M}$ phosphate buffer at $\mathrm{pH} 6.8$. SNEDDS (equivalent to $10 \mathrm{mg}$ ) was placed in dialysis bag to compare the release profile with conventional tablets ${ }^{19}$. $10 \mathrm{ml}$ of sample solution was withdrawn at predetermined time intervals, filtered through a $0.45 \mu \mathrm{m}$ membrane filter, dilute suitably and analyzed chromatographically (RPHPLC). Equal amount of fresh dissolution medium was replaced immediately after withdrawal of the test sample. Percentage cumulative drug released at different time intervals was calculated and graph plotted versus time.

\section{In vitro rat intestinal permeability study:}

Various methods employed for intestinal permeability were modified within experimental procedures described in the literature. Male albino rats (250-300 grams) were killed by overdose with pentobarbitone IV injection. To check the intra-ileum permeability, the ileum part of intestine was isolated, washed thoroughly with cold Ringer's solution to remove the mucous and lumen contents. The formulations were diluted with $1 \mathrm{ml}$ of distilled water and sample $(1 \mathrm{mg} / \mathrm{mL})$ was injected into the ileum using a syringe, making sure two sides of the intestine are tightly closed. The tissue was placed in a chamber of organ bath with continuous aeration at $37^{\circ} \mathrm{C}$. The receiver compartment was filled with $30 \mathrm{ml}$ of $0.05 \mathrm{M}$ phosphate-buffered saline $(\mathrm{pH} 6.8)$. At predetermined time intervals of $15,45,75,105,135$ and 165 minutes (up to 2.75 hours), $2 \mathrm{ml}$ of the samples were withdrawn and the drug concentration was determined by validated HPLC method ${ }^{20}$. Percentage cumulative drug absorption of drug was calculated by plotting the graph versus time. The same procedure was repeated for marketed tablet.

\section{Thermodynamic Stability Studies:}

\section{Freeze-thaw cycle:}

Freeze thawing was employed to evaluate the stability of formulations. The formulations were subjected to 3 to 4 freeze-thaw cycles, which included freezing at $4^{\circ} \mathrm{C}$ for 48 hours followed by thawing at $40^{\circ} \mathrm{C}$ for 48 hours. Centrifugation was performed at $3000 \mathrm{rpm}$ for 5 minutes $^{21}$. The formulations were then observed for phase separation. Only formulations that were stable to phase separation were selected for further studies. 


\section{Stability Studies:}

The hard gelatin capsules (size 0) filled with different formulation was placed in stability chambers (REMI, India). Stability studies at $25^{\circ} \mathrm{Cl} 60 \% \mathrm{RH}$, $30^{\circ} \mathrm{C} / 65 \% \mathrm{RH}$, and $40^{\circ} \mathrm{C} / 75 \% \mathrm{RH}$ were conducted according to ICH guidelines. Sampling was done at specified intervals over a period of 3 months for intermediate and accelerated conditions and 6 months for long-term conditions ${ }^{21}$. Drug content of the capsules was analyzed using developed RP-HPLC method.

\section{RESULTS AND DISCUSSION:}

\section{Solubility studies:}

Table 3 Solubility of Atorvastatin in various oils, surfactants and co-surfactants

\begin{tabular}{|c|c|c|}
\hline SNO & Vehicle & Solubility in $\mathbf{~ m g} / \mathbf{m l}$ \\
\hline 1 & Miglyol & 0.33 \\
\hline 2 & Oleic acid & $\mathbf{9 . 4}$ \\
\hline 3 & Iso propyl myristate & 0.73 \\
\hline 4 & Cotton seed oil olive oil & 8.36 \\
\hline 5 & Olive oil & 7.21 \\
\hline 6 & Soya oil & 4.89 \\
\hline 7 & Tween 80 & $\mathbf{7 3 . 8 7}$ \\
\hline 8 & Tween 20 & 37.14 \\
\hline 9 & Span 80 & 69.5 \\
\hline 10 & Span 20 & 26.5 \\
\hline 11 & Cremophore RH 40 & 32.4 \\
\hline 12 & PEG 400 & 93.3 \\
\hline 13 & Brij 30 & $\mathbf{5 4 . 8}$ \\
\hline 14 & Transcutol-p & 48.9 \\
\hline
\end{tabular}

Selection of right component is important prerequisite for formulation of stable SNEDDS. The drug should have good solubility in components of micro emulsion so as the precipitation of drug during shelf life of formulation and after dilution in GI lumen can be avoided. Therefore, the solubility of atorvastatin calcium was determined in various oils, surfactants and co-surfactant mixtures. The solubility results are depicted in figure I. Among the various components studied oleic acid, Brij 30 and Tween 80 showed maximum solubility $9.8 \pm 1.79,73.87 \pm 1.73$ and $54.83 \pm 0.51 \mathrm{mg} / \mathrm{ml}$ respectively. The solubility results for oil: surfactant mixtures are showed in Table 3 .

As the solubility of atorvastatin was maximum in oleic acid, Brij 30 and Tween 80 these were selected as oil and surfactant component for further development of SNEDDS. Final selection among different components would secondly be confirmed according to emulsification properties with other ingredients. Regarding surfactants and co-surfactants selection, drug solubility would come second to the main selection perspective: emulsification efficiency.

Tween 80 a non-ionic surfactant with high HLB value 15 , which has miscible with atorvastatin, being less toxic and less affected by $\mathrm{pH}$ and ionic changes in the dispersion medium. Oleic acid was selected as oily phase because it has ability of high spontaneity for emulsification and high drug loading capacity. Brij 30 (HLB-9) was selected as cosurfactant it is a medium chain mono glyceride promotes water penetration and has good solvent capacity for drugs.

Figure-1 Solubility of atorvastatin in various oils, surfactants and co-surfactants

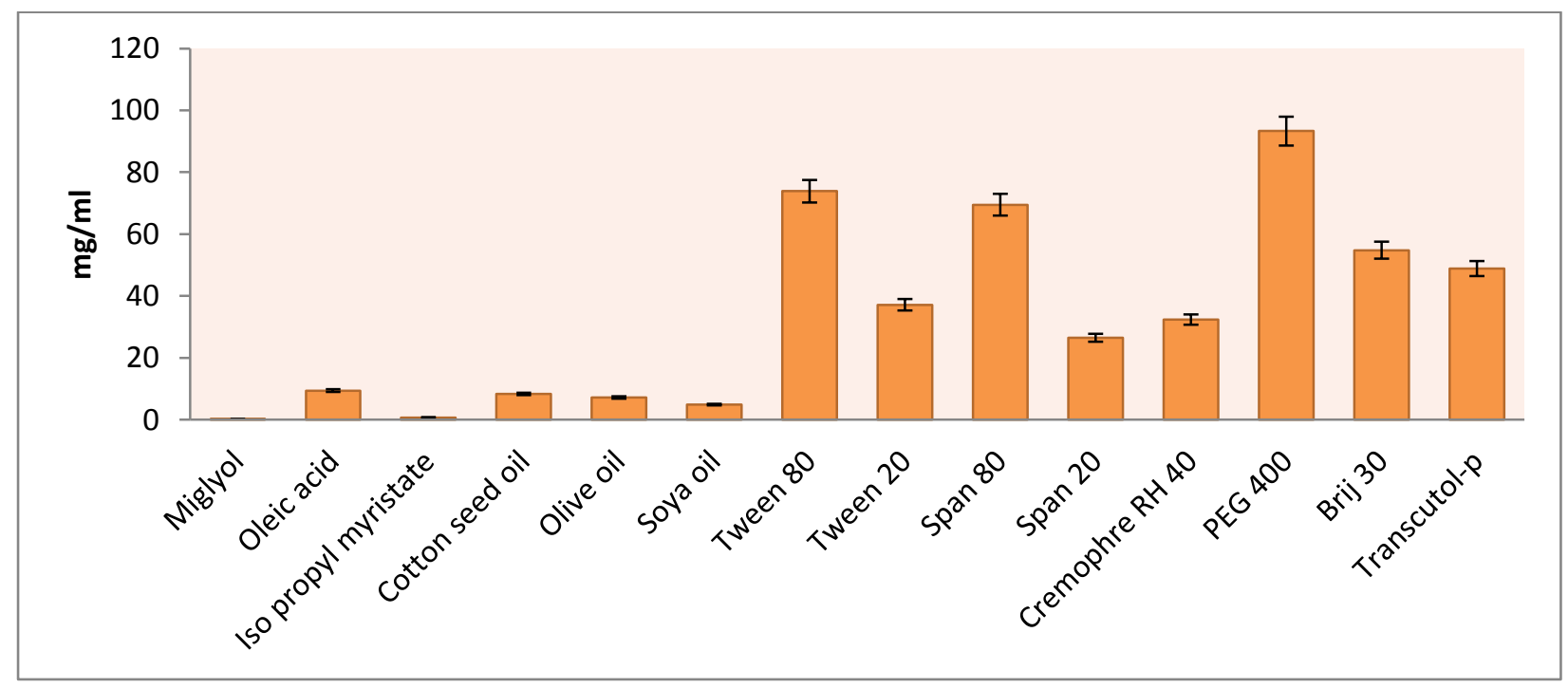

\section{Phase diagram}

Figure 2 and 3 represents the phase diagrams of oil-surfactant-water systems: (oleic acid, Tween 20: Brij 30 and water) in different ratios. These phase diagrams showed the different areas of bluish nano emulsion (NE), slightly bluish micro emulsion (ME), and coarse emulsions (ME). It can be seen that the largest micro emulsion region 
is seen when the combination of surfactant and cosurfactant are used.

Ternary phase diagrams were constructed to identify the self-emulsifying regions and also to establish the optimum concentrations of oil, surfactant and co-surfactant. From the phase diagrams, it was observed that as increasing the concentration of surfactant increased the self-emulsifying region. Emulsification region decreased with increasing the concentration of co-surfactant. Efficiency of selfemulsification was good when the surfactant concentration was more than $50 \%$. From the formulations as the concentrations of oil increases (above 35\%) showed the

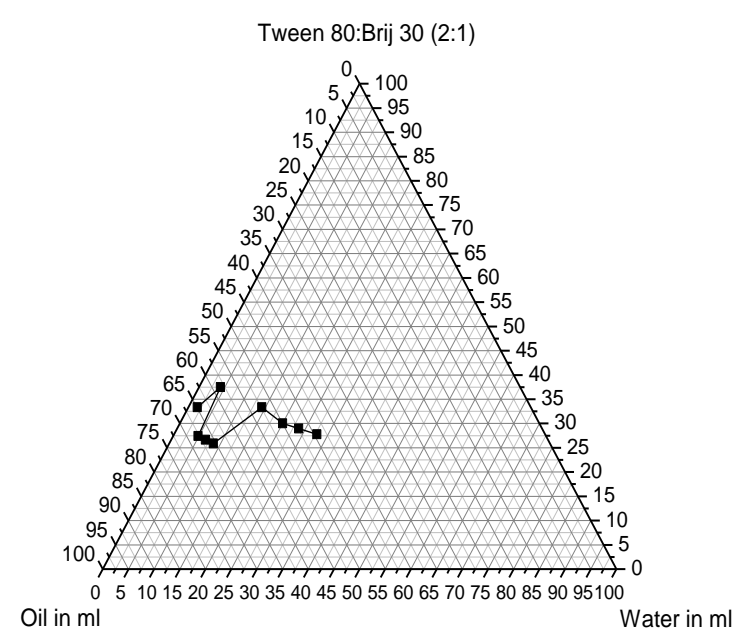

Figure 2- 2:1 ratio

\section{Characterization:}

1. Visible Assessment, Phase separation and Stability study:

Formulations BF1 to BF11 showed no crystal growth or no precipitation which formed micro emulsion upon

Table 4. Visible assessment SNEDDS after dilution and phase separation, precipitation results on storage phase separation of SNEDDS formulation. Effect of drug on phase diagram study was conducted to check the effect of emulsification region and stability of the emulsification process. Emulsification zone was narrowed as the concentration of drug increased, viscosity of the system is increased and some formulations showed gel like appearance. BF8, BF10 showed increase in the viscosity. BF16, BF18 and BF20 very viscous emulsions because the concentration of oil and surfactant concentration increases the viscosity $\mathrm{y}$ of the system increased, transparent emulsion was formed with increase in the concentration of concentration of Brij 30.
Tween 80: Brij 30 (1:2)

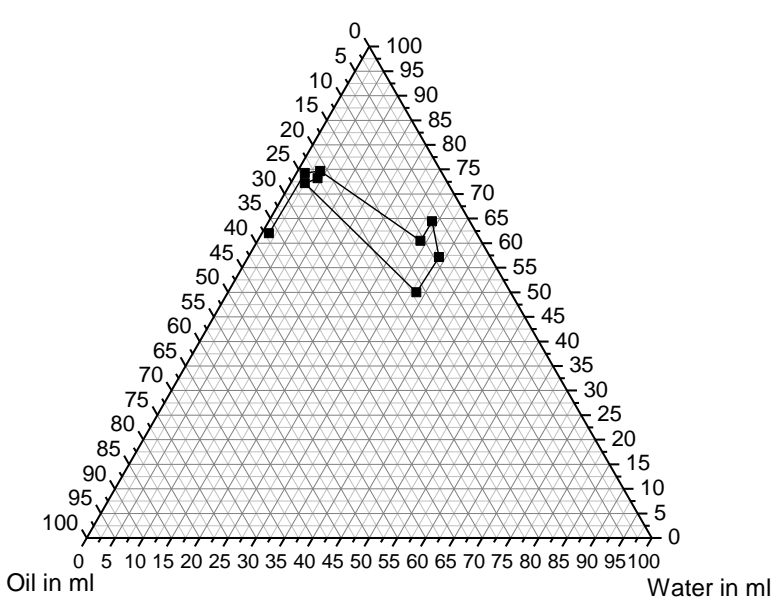

Figure 3- 1:2 ratio

dilution and was stable for 24 hours. The remaining formulations showed phase separation and precipitation. It indicates that as concentration of oil increases the stability of formulation is decreased and also increase in surfactant content the clarity is better.

\begin{tabular}{|c|c|c|c|}
\hline Formulation code & Visibility grade & Phase separation & Precipitation \\
\hline BF1 & II & X & XX \\
\hline BF2 & I & X & XX \\
\hline BF3 & II & X & XX \\
\hline BF4 & I & X & XX \\
\hline BF5 & II & X & XX \\
\hline BF6 & II & X & XX \\
\hline BF7 & II & X & XX \\
\hline BF8 & II & X & XX \\
\hline BF9 & III & X & XX \\
\hline BF10 & IV & X & XX \\
\hline BF11 & III & X & XX \\
\hline BF12 & IV & + & XX \\
\hline BF13 & V & + & ++ \\
\hline BF14 & V & + & ++ \\
\hline BF15 & V & + & ++ \\
\hline BF16 & V & + & ++ \\
\hline BF17 & V & + & ++ \\
\hline BF18 & V & + & ++ \\
\hline BF19 & V & + & ++ \\
\hline BF20 & V & ++ \\
\hline
\end{tabular}

X-- No phase separation, XX--No precipitation, +--phase separation and ++--precipitation. 


\section{Determination of Emulsification Time:}

In the study formulations (BF1-BF11) have shown spontaneity of emulsification and good stability without any signs of drug or excipient precipitation.

Table 5. Emulsification times of various SNEDDS formulations in $0.1 \mathrm{~N} \mathrm{HCl}$ and distilled water.

\begin{tabular}{|c|c|c|c|c|}
\hline \multirow{2}{*}{$\begin{array}{l}\text { Formulation } \\
\text { code }\end{array}$} & \multicolumn{2}{|c|}{$0.1 \mathrm{~N} H C l$} & \multicolumn{2}{|c|}{ Distill water } \\
\hline & $\begin{array}{c}\text { Emulsification time } \\
\text { (sec) }\end{array}$ & $\begin{array}{r}\text { Tendency for } \\
\text { emulsification }\end{array}$ & $\begin{array}{c}\text { Emulsification time } \\
\text { (sec) }\end{array}$ & $\begin{array}{l}\text { Tendency for } \\
\text { emulsification }\end{array}$ \\
\hline BF1 & 67 & good & 73 & good \\
\hline $\mathrm{BF} 2$ & 56 & good & 61 & good \\
\hline BF3 & 82 & good & 92 & good \\
\hline BF4 & 71 & good & 84 & good \\
\hline BF5 & 87 & good & 98 & good \\
\hline BF6 & 76 & good & 85 & good \\
\hline BF7 & 96 & good & 112 & bad \\
\hline BF8 & 83 & good & 91 & good \\
\hline BF9 & 119 & good & 127 & bad \\
\hline BF10 & 128 & good & 142 & bad \\
\hline BF11 & 132 & good & 156 & bad \\
\hline
\end{tabular}

Figure -2 Emulsification times of various formulations in $0.1 \mathrm{~N} \mathrm{HCl} \&$ distilled water

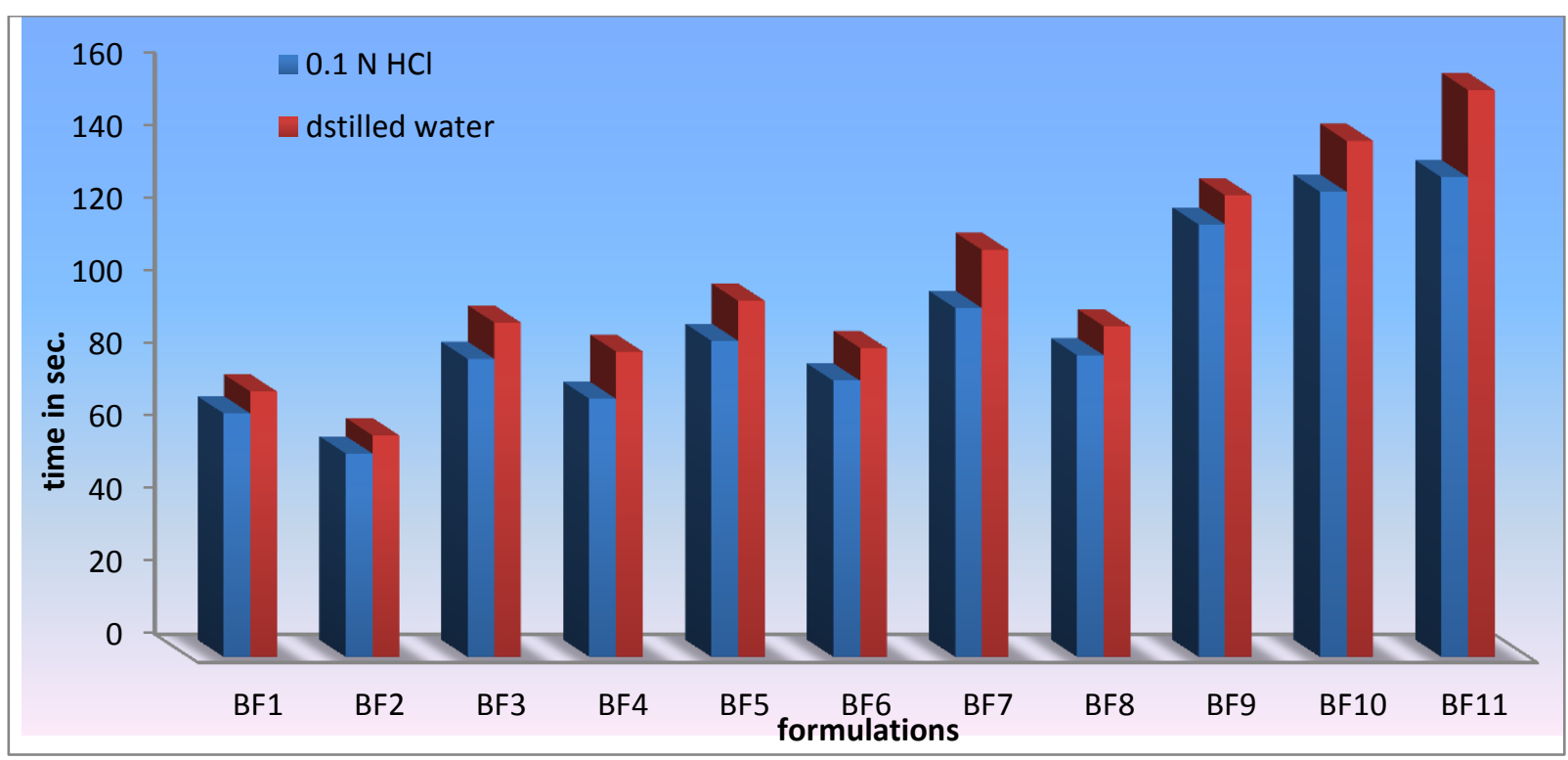

\section{Droplet size measurements:}

From the results, as the concentration of brij 30 increases uniformity of the nano emulsion decreased. Further characterizations were carried with formulations BF1, BF2, BF4 and BF6. 
Table 6. Droplet size, PDI of the SNEDDS formulations

\begin{tabular}{|c|c|c|}
\hline Formulation code & Droplet size (nm) & Poly Dispersity Index \\
\hline BF1 & 198 & 0.282 \\
\hline BF2 & 155.1 & 0.179 \\
\hline BF3 & 217 & 0.412 \\
\hline BF4 & 162.2 & 0.297 \\
\hline BF5 & 226 & 0.415 \\
\hline BF6 & 178.5 & 0.315 \\
\hline BF7 & 242 & 0.556 \\
\hline BF8 & 236.5 & 0.489 \\
\hline
\end{tabular}

Figure 3. Droplet size of nano emulsion

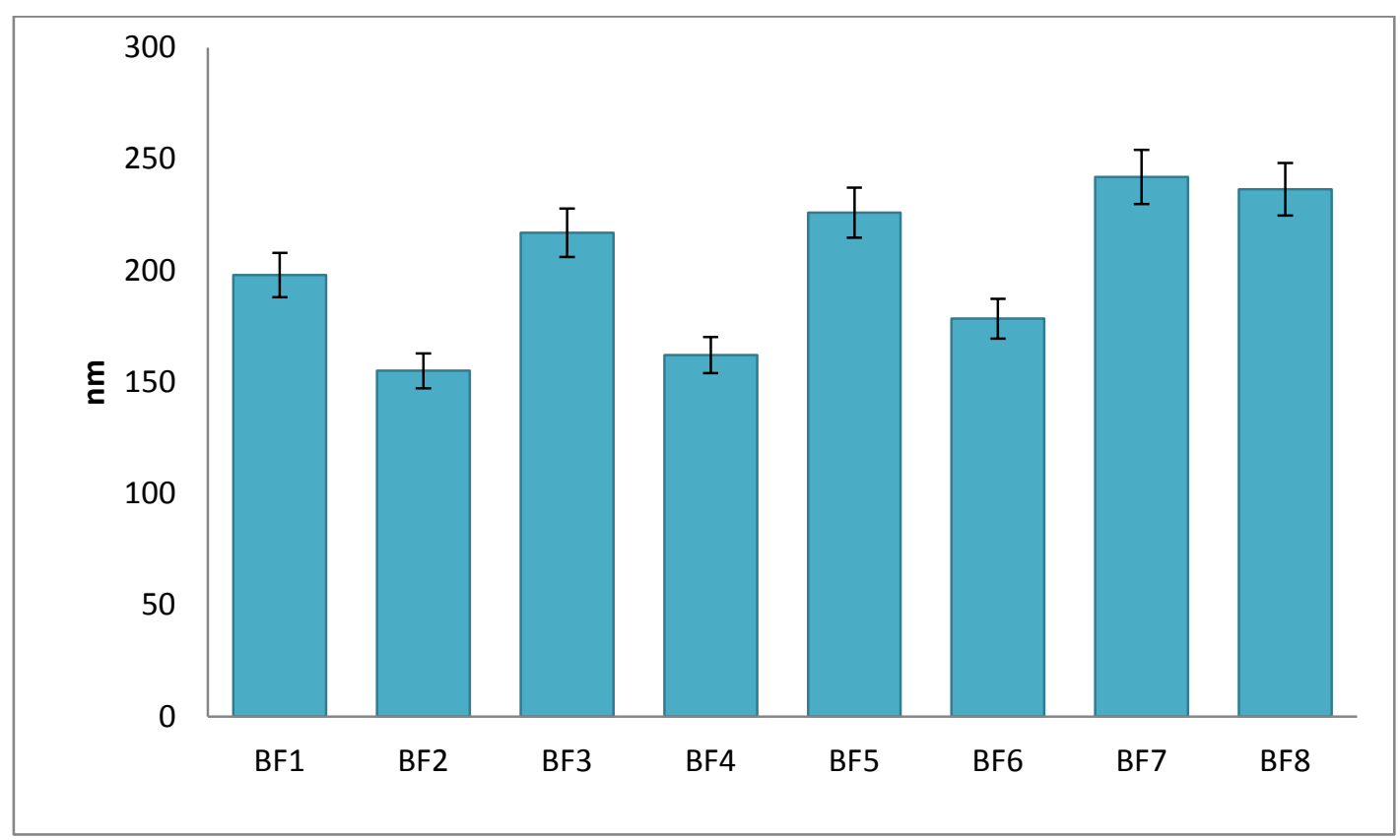

\section{Zeta potential measurement:}

Zeta potential of all SNEDDS formulation was in range of -17 to $-30 \mathrm{mV}$ in the 50 times dilution. SNEDDS formulations consist of non-ionic components and oleic acid which show relatively negative charge. Formulations BF4 and BF6 have surface charge more than $25 \mathrm{mv}$ meaning will not be affected by cell membrane charge during absorption and also can produce stable nano emulsion particles. The results were similar of phenytoin. Table 7. Zeta potential of formulations

\section{Cloud point measurement:}

\begin{tabular}{|c|c|}
\hline Formulation code & Zeta potential (mv) \\
\hline BF1 & $-16 \pm 4.35$ \\
\hline BF2 & $-18 \pm 5.65$ \\
\hline BF4 & $-24.6 \pm 6.47$ \\
\hline BF6 & $-28 \pm 5.84$ \\
\hline
\end{tabular}

Cloud points of all formulations were very high about $80^{\circ} \mathrm{C}$. In all formulations, cloudiness was reversible ossible due to dehydration of $\mathrm{POE}$ moiety, alkyl chains of surfactant system 
Table 8. Cloud point of stable SNEDDS formulation

\begin{tabular}{|c|c|}
\hline Formulation code & Cloud point \\
\hline BF1 & $74 \pm 6.52$ \\
\hline BF2 & $73 \pm 5.15$ \\
\hline BF4 & $80 \pm 4.64$ \\
\hline BF6 & $76 \pm 5.8$ \\
\hline
\end{tabular}

\section{Thermodynamic stability study:}

Thermodynamic stability study was designed to identify and avoid the metastable formulations.

The formulations were stable during centrifugation at 3500 $\mathrm{rpm}$ at alternative temperature cycles of $40^{\circ} \mathrm{c}$ and $-4^{\circ} \mathrm{c}$. There was no phase separation and precipitation observed.

\section{FTIR Studies:}

From the spectra, it is observed there is possibility of intermolecular hydrogen bonding between adjunct atorvastatin molecules. The spectrum of pure atorvastatin was equivalent to the spectra obtained by the SNEDDS indicating there were no possible incompatibilities.

Figure 4 IR spectra of pure atorvastatin
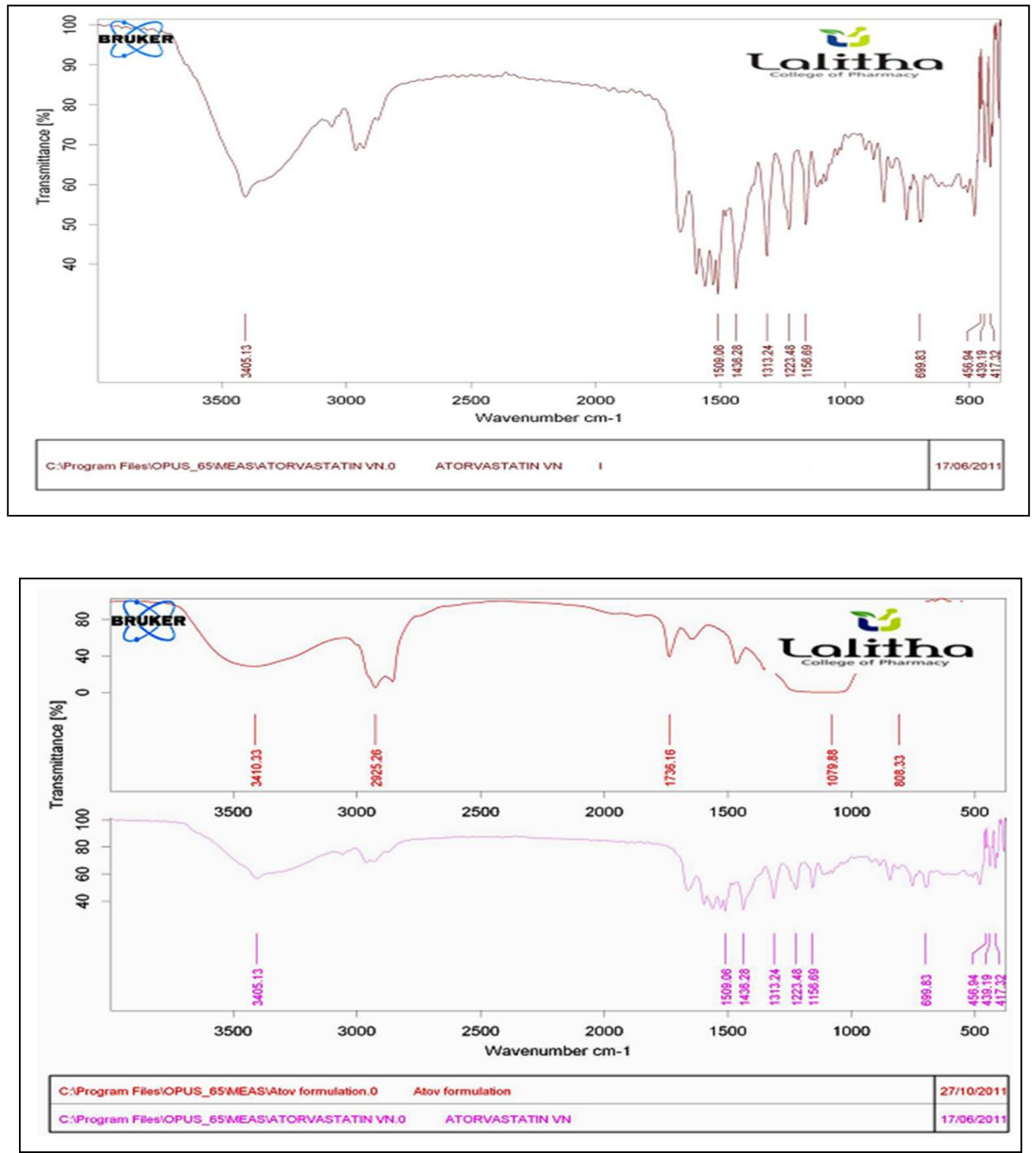


\section{Physical Analysis of globules:}

Scanning electron micrographs revealed the formation of well identified spherical globules with sharp boundaries after hydration, similar to those seen with lutein loaded novel SNEDDS. The surface characteristics of SNEDDS-derived nano emulsion are depicted in the figure 6.

Figure $6 \quad$ (a) SEM at $1 \mu \mathrm{m}$

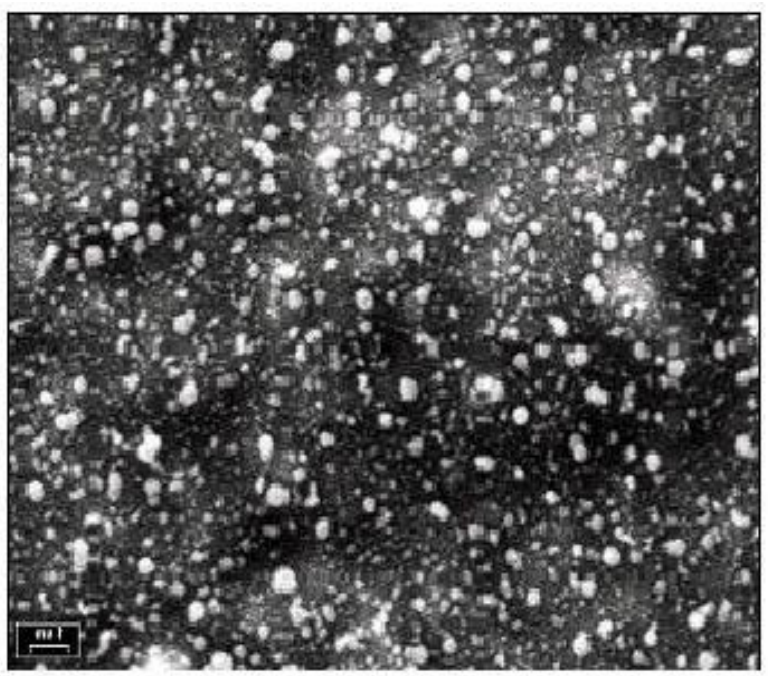

(b) SEM at $200 \mathrm{~nm}$

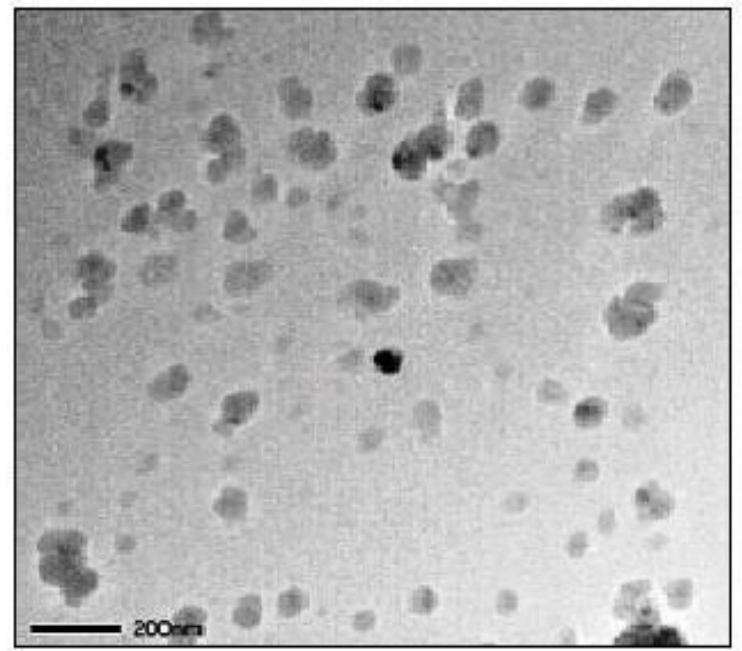

\section{Drug content:}

The drug content for the selected formulation was calculated using the standard formula.

Table 9 Percentage of drug in various formulations

\begin{tabular}{|c|c|}
\hline Formulation code & Percentage of drug \\
\hline BF1 & 99.52 \\
\hline BF2 & 98.42 \\
\hline BF4 & 99.67 \\
\hline BF6 & 99.33 \\
\hline
\end{tabular}

\section{In-vitro release studies:}

The percent cumulative release of Atorvastatin from the formulations BF4 and BF6 was found to be higher than the other formulations and marketed product (storvas ${ }^{\circledR} 10 \mathrm{mg}$ ). The percentage drug released after 90 minutes for BF4 and BF6 were $99.65 \%$ and $89.26 \%$ were as $56.86 \%$ release for marketed product. Cumulative percent drug release is high in formulation BF4 because of low viscosity and high concentration of surfactant i.e. Tween 80.

Table 10. Cumulative percent release of Atorvastatin from various formulations

\begin{tabular}{|c|c|c|c|c|c|c|}
\hline Time(min) & BF1 & BF2 & BF4 & BF6 & $\begin{array}{c}\text { crude } \\
\text { drug }\end{array}$ & $\begin{array}{c}\text { marketed } \\
\text { product }\end{array}$ \\
\hline 0 & 0 & 0 & 0 & 0 & 0 & 0 \\
\hline 5 & 24.24 & 26.28 & 39.12 & 32.46 & 8 & 16 \\
\hline 10 & 36.33 & 33.59 & 58.34 & 49.56 & 10.5 & 22.64 \\
\hline 20 & 41.54 & 42.56 & 71.65 & 68.67 & 12.88 & 26 \\
\hline 30 & 44.21 & 51.62 & 78.66 & 74.65 & 15.3 & 34.99 \\
\hline 40 & 49.63 & 56.31 & 86.89 & 79.98 & 16.98 & 41.24 \\
\hline 50 & 54.21 & 59.35 & 91.26 & 82.78 & 18.56 & 46.66 \\
\hline 60 & 58.66 & 63.3 & 94.12 & 85.55 & 21.36 & 48.54 \\
\hline 75 & 62.43 & 69.5 & 97.66 & 87.33 & 23.55 & 52.64 \\
\hline 90 & 64.99 & 73.6 & 99.65 & 89.26 & 25.86 & 56.86 \\
\hline
\end{tabular}


Figure 7 Percentage cumulative drug release of various formulations.

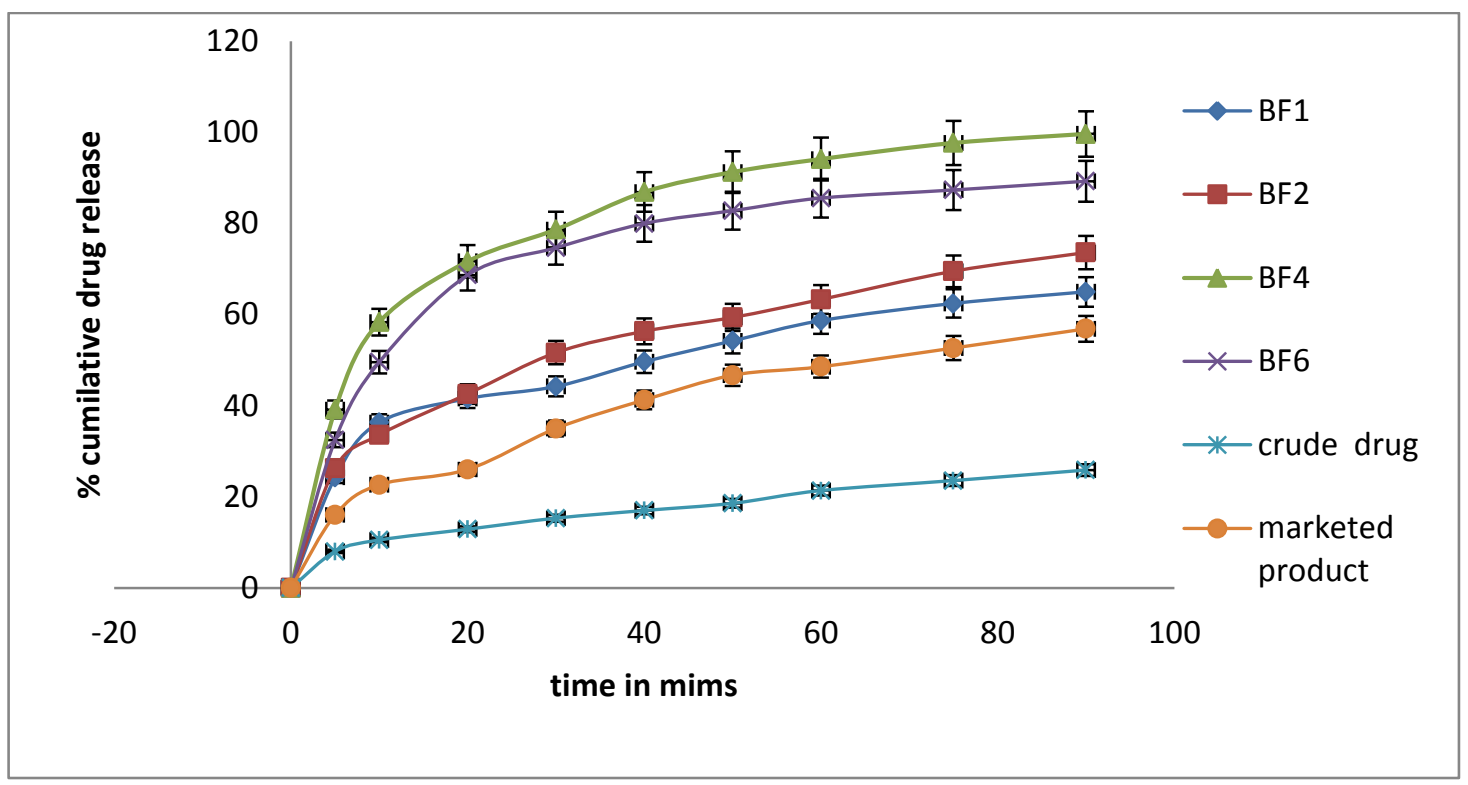

\section{In vitro rat intestinal permeability study:}

From the results it was observed that formulation BF4 has shown highest oral absorption $(86.67 \%)$ thorough intestine after 165 seconds when compared to marketed product (45.34\%). This may suggest absorption of the drug through the intestine increases with decreasing droplet size.

Table11 Percent cumulative drug absorbed through the rat skin

\begin{tabular}{|c|c|c|}
\hline Time (min) & BF4 & Marketed product \\
\hline 0 & 0 & 0 \\
\hline 15 & 24.35 & 15.25 \\
\hline 45 & 42.35 & 21.99 \\
\hline 75 & 59.33 & 32.68 \\
\hline 105 & 72.69 & 39.98 \\
\hline 135 & 81.31 & 41.45 \\
\hline 165 & 86.67 & 45.34 \\
\hline
\end{tabular}

Figure 8 Comparison of intestinal absorption between BF4 and marketed product

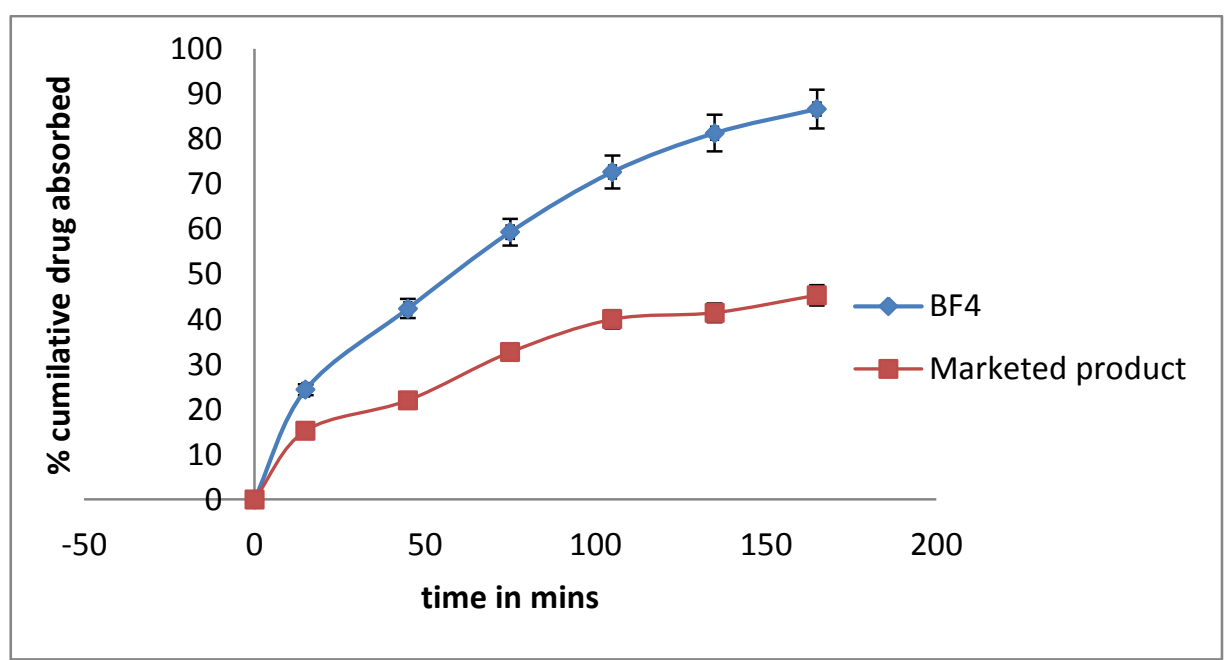




\section{Stability studies:}

The formulations BF4 and BF6 were found to be stable for 3 months and there was no significant change in the drug content, or particle size.

Table 12. Evaluation data of SNEDDS formulation subjected to stability studies at $\left(25^{\circ} \mathrm{c} / 60 \% \mathrm{RH}\right)$

\begin{tabular}{|c|c|c|c|}
\hline Formulation code & Sampling point & Droplet size size(nm) & \% drug content \\
\hline \multirow{3}{*}{ BF6 } & 0 days & 178.5 & 99.33 \\
& 45 days & 178.5 & 98.75 \\
& 3 months & 179.5 & 97.98 \\
\hline \multirow{3}{*}{ BF4 } & 0 days & 162.2 & 99.67 \\
& 45 days & 162 & 98.28 \\
& 3 months & 165 & 97.51 \\
\hline
\end{tabular}

Figure 9 Droplet sizes of the formulations after 3 months at $25^{\circ} \mathrm{c} / 60 \% \mathrm{RH}$.

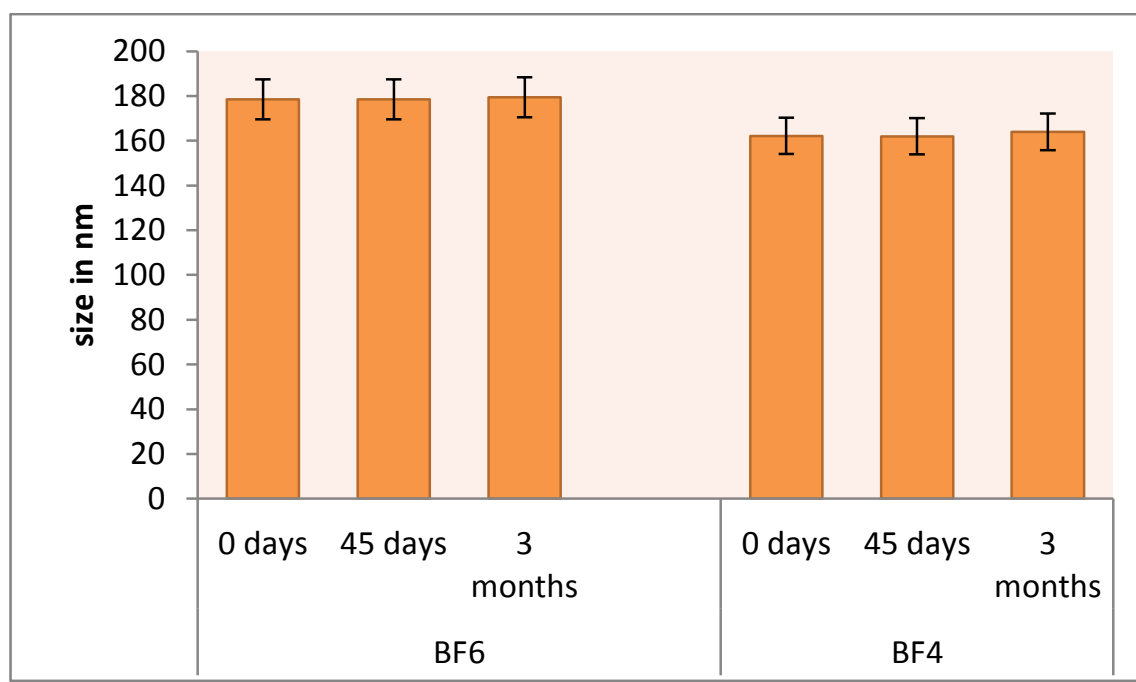

Figure 10 Drug content after storage at $25^{\circ} \mathrm{c} / 60 \% \mathrm{RH}$

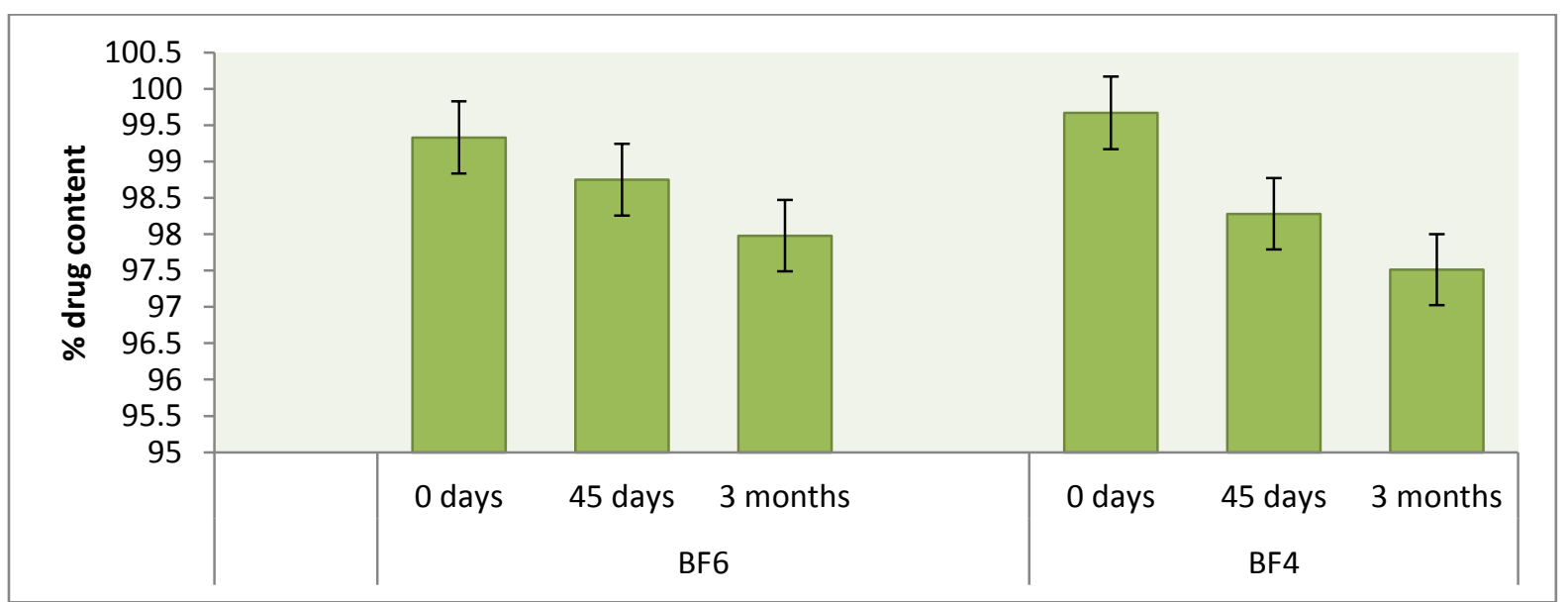

\section{CONCLUSION:}

An optimized atorvastatin loaded formulation consisting of oleic acid, Tween 80 and Brij 30 offers the advantage of good solubilisation of atorvastatin. Thus our studies confirmed that SNEDDS can be used as a possible alternative to conventional oral formulation of atorvastatin. Results further conclude that SNEDDS can be explored as a potential drug carrier for dissolution enhancement of atorvastatin and other insoluble drugs.

\section{ACKNOWLEDGMENTS:-}

The authors are thankful towards Bright labs, Hyderabad for atorvastatin gift sample. Also Dr. Prakash v diwan for project guidance and Dr. Rajeshwar Reddy, Chairman, Anurag group of institutions for providing facilities, infrastructure for carrying out research work. 


\section{REFERENCES:}

1. Pouton CW. Self-emulsifying drug delivery systems: assessment of the efficiency of emulsification. Int. J. Pharm. 27: 335-348 (1985).

2. Singh A., Chaurasiya A., Singh M., Upadhyay S., Mukherjee R., and Khar R., ExemestaneLoaded Self-Microemulsifying Drug Delivery System (SMEDDS): Development andOptimization AAPS PharmSciTech, Vol. 9, No. 2, (2008)628-634. 3. Robinson, J.R., 1996. Introduction: Semi-solid formulations for oral drug delivery. B. T.Gattefosse. 89, 11-13.

4. Yuksel, N., Karatas, A., Ozkan, Y., Savaser, A., Ozkan, SA., Baykara, T., 2003. Enhanced bioavailability of piroxicam using Gelucire 44/14 and labrasol: in vitro and in vivo evaluation.Eur. J. Pharm. Biopharm. 56, 453-459.

5. Charman, S.A., Charman, W.N., Rogge, M.C., Wilson, T.D., Pouton, C.W., 1992. Selfemulsifying drug delivery systems: formulation and biopharmaceutical evaluation of aninvestigational lipophilic compound. Pharm Res. 9, 87-93. 6. Li, P., Ghosh, A., Wagner, R.F., Krill, S., Joshi, Y.M., Serajuddin, A.T.M., 2005. Effect ofcombined use of nonionic surfactants on formation of oil in-water emulsions. Int. J. Pharm. 288,27-34.

7. Jeong-Soo Kim, Min-Soo Kim, Hee Jun Park, Shun-Ji Jin, Sibeum Lee and Sung-Joo Hwang, Physicochemical properties and bioavailability of amorphous Atorvastatin hemi- calcium using spray drying and SAS process,

DOI:10.1016/j.ijpharm.2008.04.006.

8. Patil, P., Joshi, P., Paradkar, A., 2004. Effect of formulation variables on preparation and evaluation of gelled self-emulsifying drug delivery system (SEDDS) of ketoprofen. AAPS

PharmSciTech. 5(3), E 42.

9.Kanga,K.B.Lee,S.J.Chona,K.S.Jeong,Y.S.,Yuk,H.S.Khanga,G, Development of Selfmicroemulsifying drug delivery systems for oral bioavailability enhancement of Simvastatin in Beagle Dogs Int.J.Pharm,(2004)274,6573

10.Subramanian, N., Ray, S., Ghosal, S., Bhandra, R., Moulik, S. P., (2004) Formulation design of Self-Microemulsifying drug delivery systems for improved oral bioavailability of Celecoxib, Bio, Pharm, Bull., 27(12),1993-1999.

11.Land, L. M., Li, P and Bummer, P. M., (2005), the influence of water content of triglyceride oils on the solubility of steroids, Pharm.Res.,21, No 2, 254-260.

of curcumin by self microemulsifying drug delivery systems, Int.J.Pharm, (2008),doi:10.1016/j.ijpharm.2008.12.0090
12.Wei Wu, Yang Wang, Li Que Enhanced bioavailability of silymarin by selfmicroemulsifying drug delivery system European Journal of Pharmaceutics and Biopharmaceutics 63 (2006) 288-294 13. Nazzal, S., Nutan, M., Palamakula, A., Shah, R., Zaghloul, A.A., Khan, M.A., 2002. Optimization of selfnanoemulsified tablet dosage form of ubiquinone using response surface methodology: effect of formulation ingredients. Int. J. Pharm. 240, 103-114.

14. Grove, M., Mullertz, A., Nielsen, J. L and Pedersen, G. P., (2006), Bioavailability of seocalcitol II: Development and characterization of self microemulsifying drug delivery systems (SMEDDS) for oral administration containing medium and long chain triglycerides, Eur. J.Pharm.Sci,28(3), 233-242.

15. Eman A., Albert AB, Formulation and in vitro and in vivo characterization of a phenytoin self-emulsifying drug delivery system (SEDDS), European journal of pharmaceutical sciences 35 (2008) 257-263.

16. Kim, J. Y., Young, S. K.,(2000), Enhanced absorption of Indomethacin after oral or rectal administration of Self emulsifying system containing Indomethacin torats, Int.J.Pharm,194, 81- 89. 17. Pouton, C.W., Charman, W.N., 1997. The potential of oily formulations for drug delivery to the gastro-intestinal tract. Adv. Drug Del. Rev. 25, 1-2.

18. Patil P. and Paradkar A., Porous Polystyrene Beads as Carriers for Self-Emulsifying System Containing Loratadine, AAPS PharmSciTech 2006; 7 (1) Article 28.

19. Yu, X. L., wang, T.J., Hussain, S.A., (2002), Evaluation of USP apparatus 3 for dissolution testing of immediate release products, AAPS Pharmsci., article 4(1).

20. Odeberg, J. M., Kaufmann, P., Kroon, K.G., and Hoglund P., (2003), Lipid drug delivery and rational formulation design for Lipophilic drugs with low oral bioavailability, applied to Cyclosporine, Eur. J.Pharm.Sci, 20, 375-382.

21. Patel A. and Vavia P. , Preparation and In Vivo Evaluation of SMEDDS (Self- Microemulsifying Drug Delivery System) Containing Fenofibrate, The AAPS Journal 2007; 9(3) Article 41. 22. Jing C., Bo Y., Yu Z., Weiwei Z., Houli L., Hongxiang L., Guangxi Z., Enhancement of oralabsorption 